\title{
TRITERPENES FROM CERIOPS DECANDRA (GRIFF.) W. THEOB.
}

\author{
JUDY PEREZ ${ }^{1,2}$, CHIEN-CHANG SHEN ${ }^{3}$, CONSOLACION Y. RAGASA ${ }^{1,4 *}$
}

${ }^{1}$ Department of Chemistry, De La Salle University, Manila, Philippines. ${ }^{2}$ Department of Natural Sciences, College of Science and Engineering, Ateneo de Naga University, Camarines Sur, Philippines. ${ }^{3}$ Division of Chinese Medicinal Chemistry, National Research Institute of Chinese Medicine, Ministry of Health and Welfare, Taiwan. ${ }^{4}$ Department of Chemistry, De La Salle University Science \& Technology

Complex Leandro V. Locsin Campus, Philippines. Email: consolacion.ragasa@dlsu.edu.ph

Received: 01 May 2017, Revised and Accepted: 28 July 2017

\section{ABSTRACT}

Objective: To isolate and identify the chemical constituents of Ceriops decandra.

Methods: The chemical constituents of $C$. decandra (Griff.) W. Theob. were isolated by silica gel chromatography. The structures of the isolated compounds were identified by nuclear magnetic resonance (NMR) spectroscopy.

Results: Chemical investigation of the dichloromethane extracts of the leaves of $C$. decandra has led to the isolation of $3 \beta$-E-coumaroylbetulinic acid (1), lupeol fatty acid esters (2), betulonic acid (3), betulin (4), betulinic acid (5), lupeol (6), lupenone (7), and a mixture of $3 \beta$-E-feruloyllupeol (8) and 3 $\beta$-Z-feruloyllupeol (9), and chlorophyll a (10). The structures of 1-10 were identified by comparison of their NMR data with literature data.

Conclusion: To the best of our knowledge, this is the first report on the isolation of 1-3 from $C$. decandra. Literature search revealed that the triterpenes isolated from C. decandra exhibited anticancer properties.

Keywords: Ceriops decandra, Rhizophoraceae, 3ß-E-coumaroylbetulinic acid, Lupeol fatty acid esters, Betulonic acid, Betulin, Betulinic acid, Lupeol, Lupenone, $3 \beta$-E-feruloyllupeol, 3 $\beta$-Z-feruloyllupeol.

(C) 2017 The Authors. Published by Innovare Academic Sciences Pvt Ltd. This is an open access article under the CC BY license (http://creativecommons. org/licenses/by/4. 0/) DOI: http://dx.doi.org/10.22159/ajpcr.2017.v10i11.19461

\section{INTRODUCTION}

Ceriops decandra of the family Rhizophoraceae, locally known as Malatangal, is a mangrove which commonly grows in the middle to landward parts of the mangrove swamp. The bark of this species was an important source of high-quality tannin. The sap of the bark of this tree is a source of a black dye which is used in the batik industry. A decoction of the bark is used to treat hemorrhages [1], while the bark, fruits, and leaves are employed for the treatment of hepatitis and ulcer [2]. Furthermore, $C$. decandra was reported to exhibit astringent and anti-hemorrhage properties and is used for the treatment of pain, ulcers, and hepatitis [3]. Several studies were reported on the chemical constituents of $C$. decandra. The leaves of $C$. decandra yielded lupenone, lupeol, betulinaldehyde, $3 \beta$-Z-coumaroyllupeol, $3 \beta$-E-coumaroyllupeol, 3 -epi-betulinic acid, betulin, betulinic acid, $3 \beta$-E-feruloylbetulin, 30 -nor-lup-3 $\beta$-ol-20-one, $3 \beta$-E-caffeoyllupeol, lup-20(29)-en-3 $\beta, 30$ -

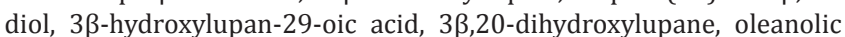
acid, ursolic acid, and $3 \beta$-E-feruloyllupeol and 3 $\beta$-Z-feruloyllupeol [4] which are of relevance to our present report. Another study reported that the leaf extracts afforded $\alpha$-amyrin, $\beta$-amyrin, lupeol, oleanolic acid, and ursolic acid [5]. The bark of $C$. decandra yielded decandrins A-K [6]; 2-(9-hydroxy-3a,5a,5b,8,8,11a-hexamethylicosahydro-1Hcyclopenta[a]chrysen-1-yl) propanoic acid (3ß-hydroxylupan-29oic acid) [7]; d-catechin, leucoanthocyanidins [4]; procyanidin [8]; decandrinin [9]; (-)-syringaresinol, (-)-pinoresinol, $\beta$-sitosterol, stigmasterol, palmitic acid, and 3,4-dihydroxybenzoic acid Et ester [10]; and 7,13-abietadien-3 $\beta$-ol, 7-oxodehydro-abietinol, margocin, 3 $\beta$-hydroxy-abieta-8,11,13-trien-7-one, 15,18-dihydroxyabieta8,11,13-trien-7-one, 73,18-dihydroxy dehydroabietanol, 4-epitriptobezene L, $7 \alpha$, 18-dihydroxydehydroabietanol, sabiperone E, 13ß,18-dihydroxy-abiet-8(14)-ene-7-one, ent-labd-8(17),13E-dien-

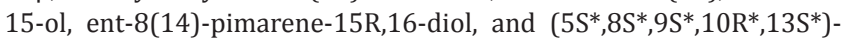
3-hydroxy-16-nor-2-oxodolar-3-ene-15-oic acid [11]. Furthermore, the wood extract of $C$. decandra yielded $3 \beta, 13 \beta$-dihydroxy-8-abietaen- 7-one and 3 3 -hydroxy-8,13-abietadien-7-one [12]. Other studies reported the isolation of ceriopsin A-D [13], ceriopsin E [14], and ceriopsin $\mathrm{F}$ and $\mathrm{G}$ [15] from the roots.

This study is part of our research on the chemical constituents of the mangroves found in the Philippines. We earlier reported the isolation of ursolic acid and squalene from the leaves and oleanolic acid, ursolic acid, $\alpha$-amyrin cinnamate, $\beta$-amyrin cinnamate, $\beta$-sitosterol, and stigmasterol from the fruit; lupeol, oleanolic acid, ursolic acid, $\beta$-sitosterol, and stigmasterol from the twigs of Sonnerata alba [16]. We report herein the isolation of $3 \beta-\mathrm{E}-$ coumaroylbetulinic acid (1), lupeol fatty acid esters (2), betulonic acid (3), betulin (4), betulinic acid (5), lupeol (6), lupenone (7), and a mixture of $3 \beta$-E-feruloyllupeol (8) and $3 \beta$-Z-feruloyllupeol (9), and chlorophyll a (10). The chemical structures of 1-9 are presented in Fig. 1. To the best of our knowledge, this is the first report on the isolation of 1-3 from C. decandra.

\section{METHODS}

\section{General experimental procedure}

Nuclear magnetic resonance (NMR) spectra were recorded on a Varian VNMRS spectrometer in $\mathrm{CDCl}_{3}$ at $600 \mathrm{MHz}$ for ${ }^{1} \mathrm{H}$ NMR and $150 \mathrm{MHz}$ for ${ }^{13} \mathrm{C}$ NMR spectra. Column chromatography was performed with silica gel 60 (70-230 mesh). Thin-layer chromatography (TLC) was performed with plastic backed plates coated with silica gel $\mathrm{F}_{254}$ and the plates were visualized by spraying with vanillin $/ \mathrm{H}_{2} \mathrm{SO}_{4}$ solution followed by warming.

\section{Sample collection}

Samples of the leaves of $C$. decandra (Griff.) W. Theob. were collected from the mangrove swamp of Caramoan, Camarines Sur Philippines in September 2016. The samples were authenticated at the Botany Division, Philippine National Museum. 


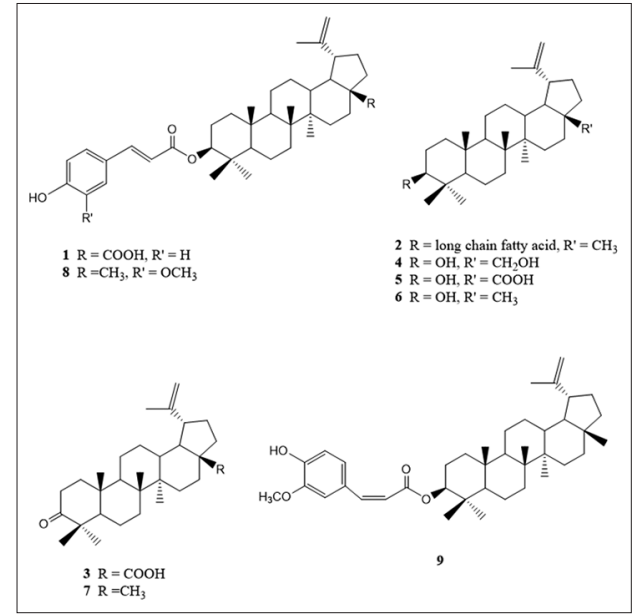

Fig. 1: Chemical structures of $3 \beta$-E-coumaroylbetulinic acid (1), lupeol fatty acid esters (2), betulonic acid (3), betulin (4), betulinic acid (5), lupeol (6), lupenone (7), 3及-E-

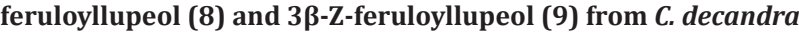

\section{General isolation procedure}

A glass column 12 inches in height and 0.5 inch internal diameter was used for the chromatography. The crude extracts were fractionated by silica gel chromatography using increasing proportions of acetone in $\mathrm{CH}_{2} \mathrm{Cl}_{2}$ at $10 \%$ increment by volume as eluents. $5 \mathrm{ml}$ fractions were collected. All fractions were monitored by TLC. Fractions with spots of the same $R_{f}$ values were combined and rechromatographed in appropriate solvent systems until TLC pure isolates were obtained. Final purifications were conducted using Pasteur pipettes as columns. $1 \mathrm{ml}$ fractions were collected.

Isolation of the chemical constituents from the leaves of $C$. decandra The air-dried $C$. decandra leaves (223.8 g) were ground in a blender, soaked in $\mathrm{CH}_{2} \mathrm{Cl}_{2}$ for 3 days and then filtered. The solvent was evaporated under vacuum to afford a crude extract $(4.0 \mathrm{~g})$ which was chromatographed using increasing proportions of acetone in $\mathrm{CH}_{2} \mathrm{Cl}_{2}$ at $10 \%$ increment by volume. The $10 \%$ and $20 \%$ acetone in $\mathrm{CH}_{2} \mathrm{Cl}_{2}$ fractions were rechromatographed $(3 \times)$ using $2.5 \%$ EtOAc in petroleum ether to afford $2(1.9 \mathrm{mg})$. The $30 \%$ acetone in $\mathrm{CH}_{2} \mathrm{Cl}_{2}$ fraction was rechromatographed $(2 \times)$ using $7.5 \%$ EtOAc in petroleum ether to yield $8(10.6 \mathrm{mg})$ and a mixture of 8 and $9(1.7 \mathrm{mg})$ after washing with petroleum ether. The $50 \%$ acetone in $\mathrm{CH}_{2} \mathrm{Cl}_{2}$ fraction was rechromatographed using $10 \%$ EtOAc in petroleum ether. The less polar fractions were combined and rechromatographed using $10 \%$ EtOAc in petroleum ether to yield $1(7.2 \mathrm{mg})$ and $7(1.8 \mathrm{mg})$ after washing with petroleum ether. The more polar fractions were combined and rechromatographed using 15\% EtOAc in petroleum ether to afford $3(6.5 \mathrm{mg})$ and a mixture of 4 and $5(2.0 \mathrm{mg})$ after washing with petroleum ether. The $60 \%$ acetone in $\mathrm{CH}_{2} \mathrm{Cl}_{2}$ fraction was rechromatographed using $12.5 \%$ EtOAc in petroleum ether, followed by $15 \%$ EtOAc in petroleum ether. The fractions eluted with 12.5\% EtOAc in petroleum ether were combined and rechromatographed in the same solvent to yield $6(24.1 \mathrm{mg})$. The fractions eluted with 15\% EtOAc in petroleum ether were combined and rechromatographed using the same solvent to afford $10(9.3 \mathrm{mg})$ after washing with petroleum ether, followed by $\mathrm{Et}_{2} \mathrm{O}$. The more polar fractions were combined and rechromatographed $(2 \times)$ using the same solvent to yield $4(2.4 \mathrm{mg})$ after washing with petroleum ether.

\section{RESULTS AND DISCUSSION}

Silica gel chromatography of the dichloromethane extracts of the leaves of $C$. decandra yielded 1-10. The NMR spectra of 1 are in accordance with data reported in the literature for $3 \beta$-E-coumaroylbetulinic acid (1) [17]; 2 for lupeol fatty acid esters [18], 3 for betulonic acid [19], 4 for betulin [20], 5 for betulinic acid [21], 6 for lupeol [16],

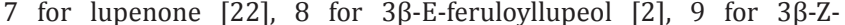
feruloyllupeol [2], and 10 for chlorophyll a [23].

Literature search revealed that the triterpenes isolated from C. decandra exhibited anticancer properties. Betulinic acid (5) and its derivatives,

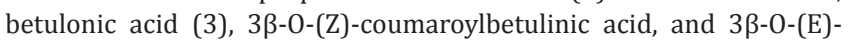
coumaroylbetulinic acid (1) were found to be catalytic inhibitors of Topo II activities with $\mathrm{IC}_{50}$ values ranging from 0.38 to $58 \mu \mathrm{M}$. The acylation of the $\mathrm{OH}$ group at $\mathrm{C}-3$ of betulinic acid exhibited stronger Topo II inhibitory activity [24]. Reviews on anticancer properties of betulinic acid (5) and its derivatives have been provided [25-30]. A review on the anticancer and chemopreventive potential of betulin (4) in vitro and in vivo has also been provided [31].

\section{ACKNOWLEDGMENT}

A research grant from De La Salle University Science Foundation, through the University Research Coordination Office, is gratefully acknowledged.

\section{REFERENCES}

1. Ceriops Decandra (PROSEA). Plant Use. Downloaded Fromuses. Available from: http://www.Plantnet-project.org/en/Ceriops_decandra (PROSEA). [Last accessed on 2017 Apr 22].

2. Revathi P, Senthinath JJ, Thirumalaikolundusubramanian P, Prabhu N. An overview of antidiabetic profile of mangrove plants. Int J Pharm Pharm Sci 2014;6(3):1-5

3. Salini G. Pharmacological profile of mangrove endophytes-a review. Int J Pharm Pharm Sci 2015;7(1):6-15.

4. Ponlimangini C, Thongdeeying P. Lupane-triterpene esters from the leaves of Ceriops decandra (Griff.) Ding Hou. Aust J Chem 2005;58:615-8.

5. Ghosh A, Misra S, Dutta AK, Choudhury A. Pentacyclic triterpenoids and sterols from seven species of mangrove. Phytochemestry 1985;24:1725-7.

6. Wang H, Li MY, Satyanandamurty $\mathrm{T}$, Wu J. New diterpenes from a Godavari mangrove, Ceriops decandra. Planta Med 2013;79(8):666-72.

7. Thongdeeying P, Chantrapromma S, Fun HK, Anjum S, Ali S, Ponglimanont C. 2-(9-Hydroxy-3a,5a,5b,8,8,11a-hexamethylicosahydro-1H-cyclopenta[a]chrysen-1-yl)propanoic acid (3[beta]hydroxylupan-29-oic acid). Acta Crystallogr Sec E Struct Rep Online 2005;61:1861-3.

8. Seshadri TR, Trikha RK. Procyanidins of Ceriops roxburghiana and Rhizophora conjugata. Indian J Chem 1971;9:928-30.

9. Wang H, Li MY, Katele FZ, Satyanandamurty T, Wu J, Bringmann G. Decandrinin, an unprecedented C9-spiro-fused 7,8-seco-ent-abietane from the Godavari mangrove Ceriops decandra. Beilstein J Org Chem 2014; 10:276-81.

10. Wang H, Zou K, Wu J. Chemical constituents of barks of Ceriops decandra. Huazhong Shifan Daxue Xuebao Ziran Kexueban 2013;47:794-6.

11. Wang $\mathrm{H}$, Wu J. Diterpenoids from barks Ceriops decandra. Zhongcaoyao 2013;44:532-6.

12. Simlai A, Mukherjee K, Mandal A, Bhattacharya K, Samanta A, Roy A. Partial purification and characterization of an antimicrobial activity from the wood extract of mangrove plant Ceriops decandra. EXCLI J 2016;15:103-12.

13. Anjaneyulu AS, Rao VL. Ceriopsins A-D, diterpenoids from Ceriops decandra. Phytochemistry 2002;60(8):777-82.

14. Anjaneyulu AS, Rao VL, Lobkovsky E, Clardy J. Ceriopsin E, a new epoxy ent-kaurene diterpenoid from Ceriops decandra. J Nat Prod 2002;65(4):592-4.

15. Anjaneyulu AS, Rao VL. Ceriopsins F and G, diterpenoids from Ceriops decandra. Phytochemistry 2003;62(8):1207-11

16. Ragasa CY, Ebajo VD Jr, de Los Reyes MM, Mandia EH, Brkljača R, Urban S. Triterpenes and sterols from Sonneratia alba. Int J Curr Pharm Rev Res 2014;6:256-61.

17. Rashid MA, Gray AI, Waterman PG, Armstrong JA. Coumarins from Phebalium tuberculosum ssp. Megaphyllum and Phebalium filifolium. J Nat Prod 1992;55(7):851-8

18. Mallavadhani UV, Mahapatra A, Jamil K, Reddy PS. Antimicrobial activity of some pentacyclic triterpenes and their synthesized 3-O-lipophilic chains. Biol Pharm Bull 2004;27(10):1576-9. 
19. Haavikko R, Nasereddin A, Sacerdoti-Sierra N, Kopelyanskiy D, Alakurtti S, Tikka M, et al. Heterocycle-fused lupane triterpenoids inhibit Leishmania donovani amastigotes. Med Chem Commun 2014;5:445-51.

20. Ragasa CY, Lim F, Raga DD, Shen CC. Hypoglycemic potential of triterpenes from Alstonia scholaris. Pharm Chem J 2013;47:54-8.

21. Khaliq S, Volk FJ, Frahm AW. Phytochemical investigation of Perovskia abrotanoides. Planta Med 2007;73(1):77-83.

22. Prakash CV, Prakash I. Isolation and structural characterization of lupane triterpenes from Polypodium vulgare. Res J Pharm Sci 2012;1:23-7.

23. Ragasa CY, de Jesus J. Porphyrins and polyprenols from Macaranga tanarius. Res J Pharm Biol Chem Sci 2014;5:701-8.

24. Wada S, Tanaka R. Betulinic acid and its derivatives, potent DNA topoisomerase II inhibitors, from the bark of Bischofia javanica. Chem Biodivers 2005;2:689-94.
25. Fulda S. Betulinic acid: A natural product with anticancer activity. Mol Nutr Food Res 2009;53(1):140-6

26. Tripathi L, Kumar P, Singh R. A review on extraction, synthesis and anticancer activity of betulinic acid. Curr Bioact Compd 2009;5:160-8.

27. Moghaddam MG, Ahmad FB, Samzadeh-Kermani A. Biological activity of betulinic acid: A review. Pharmacol Pharm 2012;3:119-23.

28. Lee SY, Kim HH, Park SU. Recent studies on betulinic acid and its biological and pharmacological activity. EXCLI J 2015;14:199-203.

29. Periasamy G, Teketelew G, Gebrelibanos M, Sintayehu B, Gebrehiwot M, Karim A, et al. Betulinic acid and its derivatives as anti-cancer agent: A review. Arch Appl Sci Res 2014;6:47-58.

30. Yogeeswari P, Sriram D. Betulinic acid and its derivatives: A review on their biological properties. Curr Med Chem 2005;12(6):657-66.

31. Król SK, Kielbus M, Rivero-Müller A, Stepulak A. Comprehensive review on betulin as a potent anticancer agent. Biomed Res Int $2015 ; 2015: 584189$. 